\title{
DIRECT ARTERIAL PRESSURE MONITORING FROM THE DORSALIS PEDIS ARTERY*
}

\author{
W.E. Spoerel, P. Deimling, and R. Aitken $\dagger$
}

FOR THE PAST DECADE it has been our practise to use controlled hypotension to about $40 \mathrm{~mm} \mathrm{Hg}$ mean pressure for operations on intracranial aneurysms and cerebral vascular malformations. Direct pressure monitoring by means of an intraarterial cannula has been considered essential for the safe conduct of this procedure. Cannulation of the radial artery is commonly used; but prolonged cannulation of this artery has been associated with thrombosis which has led to serious problems in the event of a poor collateral circulation to the palmar arch through the ulnar artery. Furthermore, in neurosurgical operations the upper part of the body is usually not easily accessible to the Anaesthetist and this may cause problems in maintaining a secure arterial line at the wrist.

Since the patient's lower extremities are quite accessible, we began to use the dorsalis pedis artery with increasing frequency for obtaining arterial samples for blood gas determinations and found that it was often possible to cannulate the dorsalis pedis artery with an 18 or 20 gauge plastic cannula. At the present time, cannulation of the dorsalis pedis artery is our method of choice of establishing an arterial line for blood pressure monitoring in controlled hypotension; the radial artery is only used if this approach is not possible.

Although we have not observed any complications from this approach, it was thought desirable to examine the collateral circulation in case of occlusion of the dorsalis pedis artery and to re-assure ourselves that the pressure readings obtained in the dorsalis pedis artery were reliable indications of the patient's blood pressure.

\section{Anatomy of the Arterial Supply of the Foot}

The classical description of the arterial supply of the foot involves a three-artery distributing system with extensive anastomoses which provide for good collateral circulation ${ }^{1-3}$. The three distributing arteries are the anterior tibial, posterior tibial and peroneal arteries (Figure 1).

The posterior tibial artery is the larger terminal branch of the popliteal artery. Coursing downwards and medially through the lower leg, it ends midway between the medial malleolus and the most prominent part of the heel. Here it divides to form the medial and lateral plantar arteries (Figure 2).

The medial plantar artery passes forwards along the medial side of the foot and ends by uniting with the branch of the first plantar metatarsal artery to the medial side of the big toe.

The lateral plantar artery, the larger of the two plantar vessels and the most important in terms of collateral circulation, passes obliquely across the sole of the

'Presented at the Annual Meeting of the Canadian Anaesthetists' Society in St. John's, Newfoundland, June 17-20, 1974.

tDepartment of Anaesthesia, University of Western Ontario and University Hospital, London, Canada. 


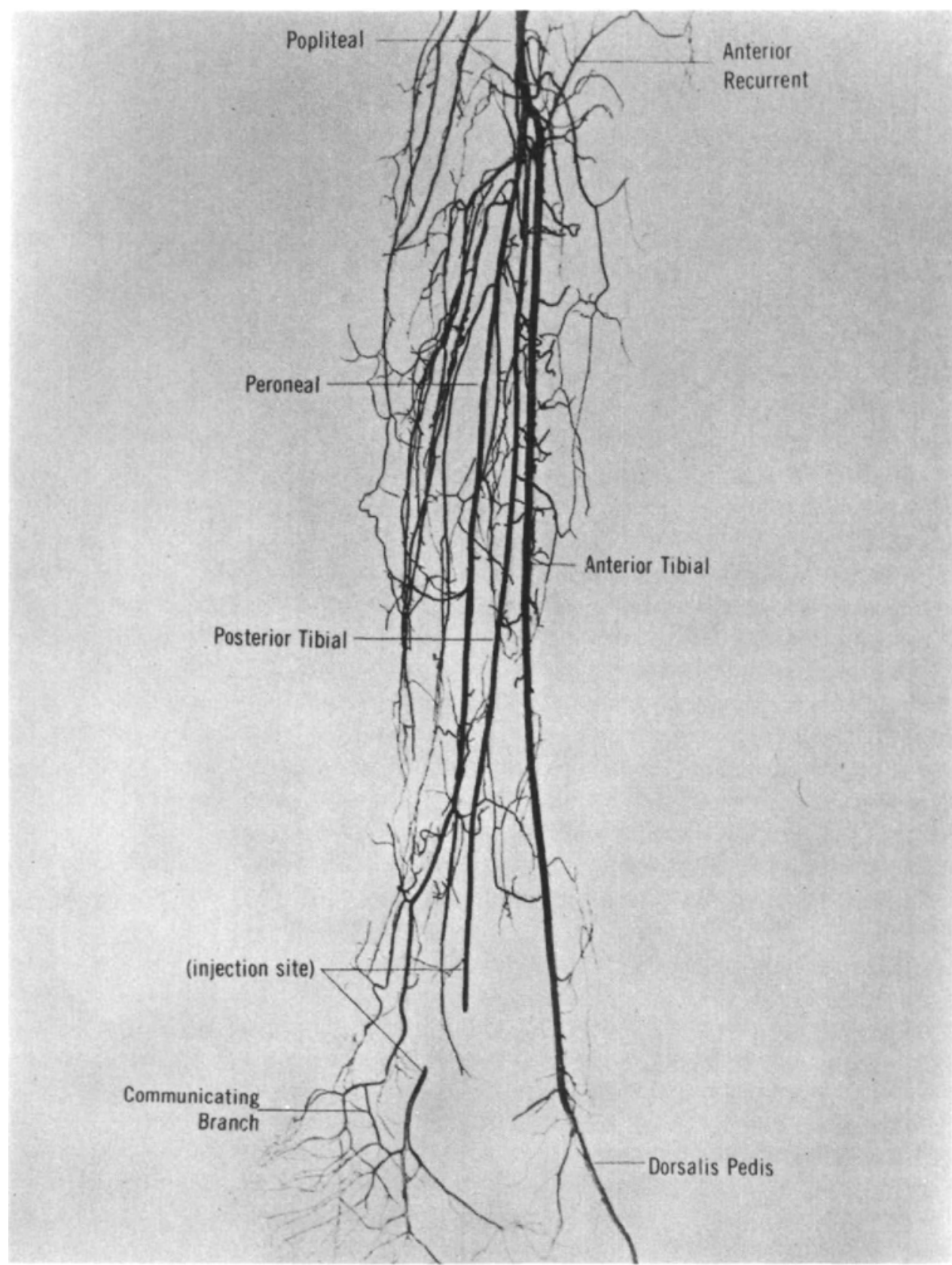

Figure 1. Cast of arteries of lower leg (from Conrad: Functional Anatomy of the Circulation to the Lower Extremities, Year Book Medical Publications Inc., Chicago, 1971. With permission of the Author and the Publisher).

foot to the base of the 5th metatarsal. It arches across the foot at the level of the metatarsal bones to the interval between the first and second metatarsals. Here it unites with the deep plantar branch of the dorsalis pedis artery to form the plantar arch.

The plantar arch is responsible for both metatarsal branches as well as per- 


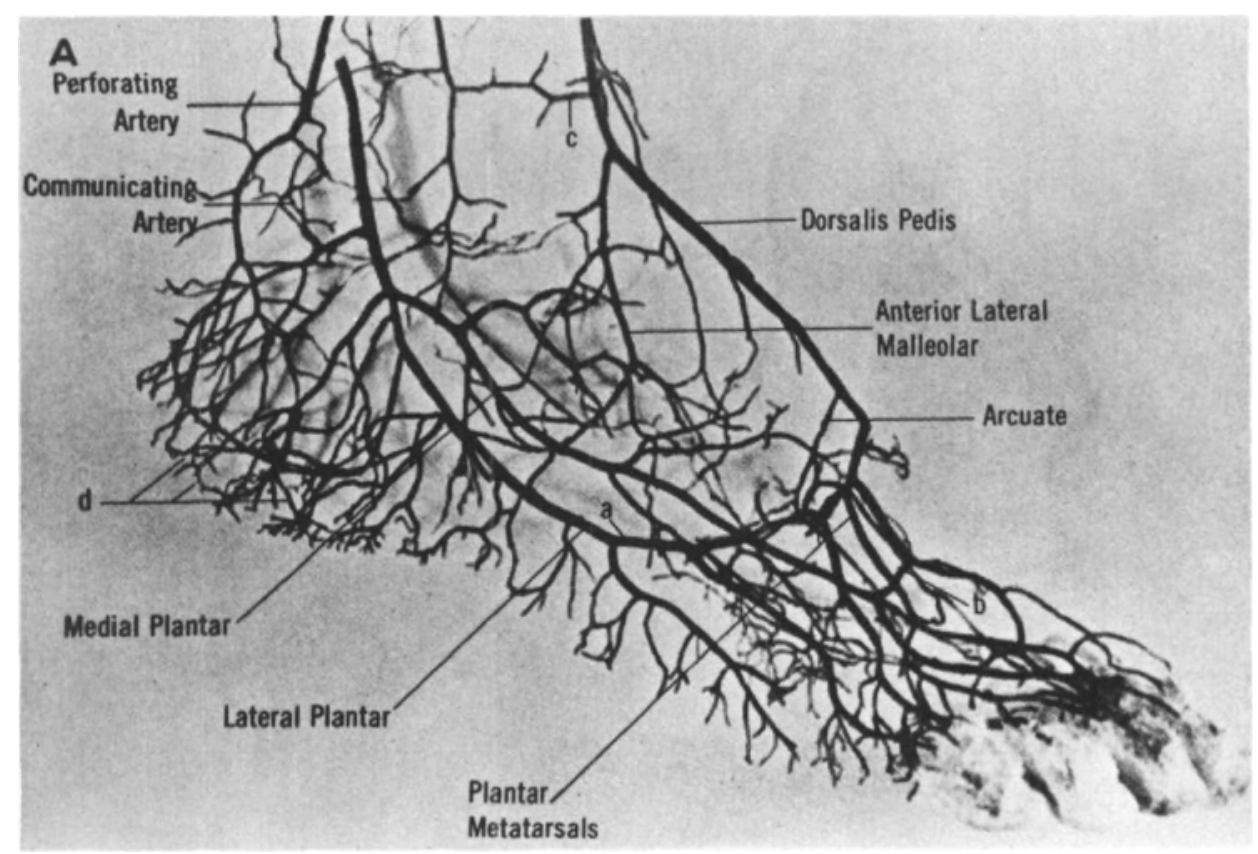

Ficune 2. Cast of arteries of the foot, lateral aspect (from Conrad' with permission of the Author and Publisher).

forating branches which unite with the dorsal metatarsal arteries. Note that the plantar metatarsals also send out perforating branches which anastomose with corresponding dorsal metatarsals. In this way, extensive connections between dorsal and plantar arterial systems are formed.

The peroneal artery, the largest branch of the posterior tibial, contributes to an extensive anastomosis about the ankle joint as well as supplying the nutrient artery of the fibula. A perforating branch passes through the interosseous membrane of the leg $5 \mathrm{~cm}$ above the lateral malleolus and joins with the anterior lateral malleolar artery. Occasionally ( 3 per cent in a study by $\mathrm{Huber}^{+}$) the dorsalis pedis artery is actually formed by the perforating peroneal branch.

The anterior tibial artery is the other terminal branch of the popliteal artery. Its continuation in the foot is known as the dorsalis pedis artery. The anterior medial and anterior lateral malleolar arteries branch from the anterior tibial artery about $5 \mathrm{~cm}$ proximal to the ankle joint and provide an important anastomosis around the ankle between the anterior and posterior tibial arteries.

The dorsalis pedis artery (Figure 3 ) passes along the medial side of the dorsum of the foot to the lst intermetatarsal space where it divides to form the 1st dorsal metatarsal and the deep plantar arteries. The deep plantar artery penetrates into the sole of the foot at this point and unites with the lateral plantar artery to complete the plantar arch.

The dorsalis pedis gives off tarsal branches to contribute to the malleolar network as well as the arcuate artery responsible for the $2 \mathrm{nd}, 3 \mathrm{rd}$ and 4 th dorsal metatarsal arteries.

Variations in this arterial pattern are the rule rather than the exception. In 


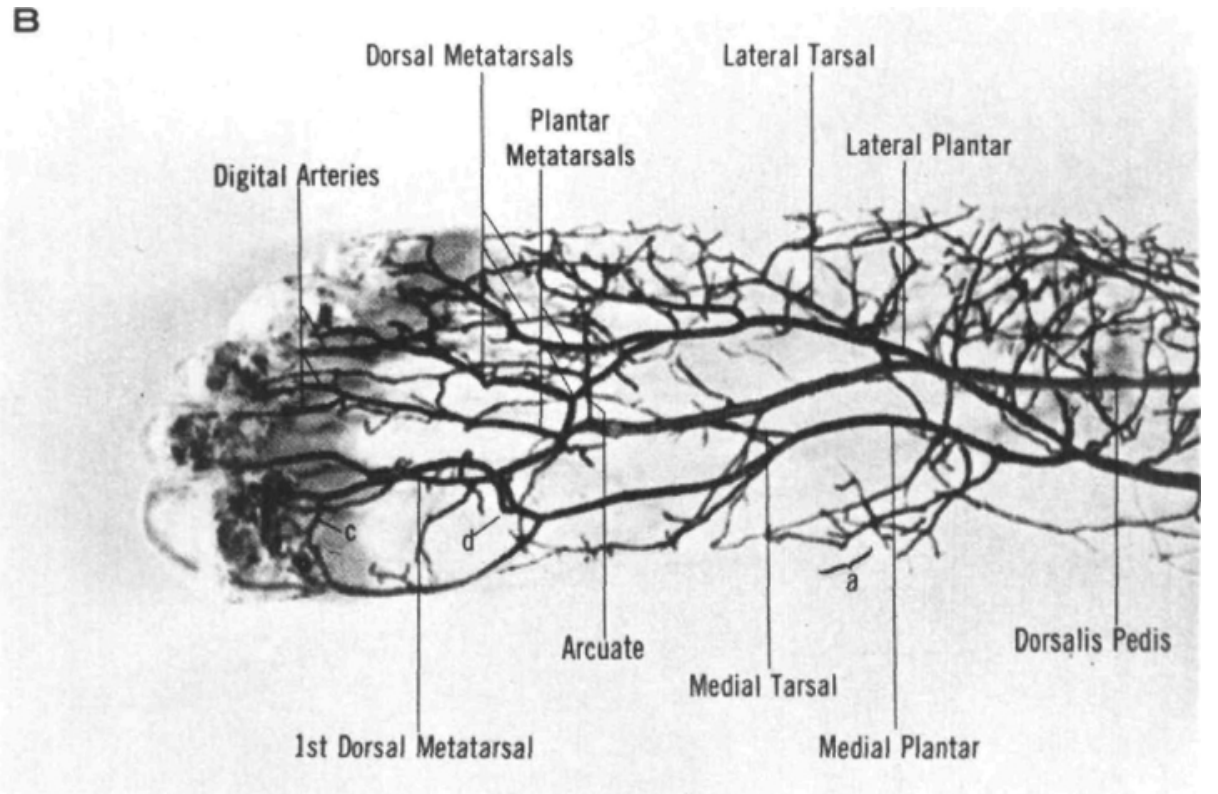

Figure 3. Cast of arteries of the foot, dorsal aspect (from Conrad', with permission of the Author and Publisher).

Huber's study ${ }^{4}$ only 11 of 200 feet dissected showed the classical pattern. However, there was no other arrangement which was found in more than 9 instances. In addition, only 63.4 per cent of these variations were bilateral.

With particular reference to the dorsalis pedis artery, 73.5 per cent of specimens followed the usual textbook description outlined previously. Nine per cent of cases deviated laterally or medially from this location and in 12 per cent the dorsalis pedis artery was absent. The dorsalis pedis artery was actually a continuation of the perforating peroneal branch of the posterior tibial artery in 3 per cent of specimens.

In spite of this wide variation, Huber found that he could superimpose 98 per cent of his specimens upon one basic pattern. The individual appearance of each dissection depended simply on which vessels were of significant calibre.

\section{Plethysmography Study}

In order to assess the effect of occlusion of the dorsalis pedis artery the following method was used:

The pulse pick-up of a Hewlett Packard Monitor was attached to the second toe of the foot and the signal was recorded on the oscilloscope as well as on a polygraph. The second toe was chosen mainly because it provided the best fit for this type of pulse pick-up.

After obtaining the normal pulse wave, both arteries were compressed manually at the ankle until the plethysmograph no longer registered a wave; then either the dorsalis pedis artery or the posterior tibial artery were released while keeping the 
alternate artery occluded. Both arteries were then occluded again and the reverse process was carried out. Care was taken to avoid any pressure on the sole of the foot that might possibly interfere with the plantar arch circulation.

This technique has been used for quite some time in our hospital to evaluate the adequacy of collateral circulation in the hand by alternately occluding the radial and ulnar arteries at the wrist.

The sensitivity of this technique was tested in five patients where a blood pressure cuff was applied to the thigh and a comparison was made between measuring the systolic blood pressure by palpating the popliteal artery and by observing disappearance and re-appearance of the plethysmographic pulse wave.

The two measurements coincided in all five patients.

\section{Results}

With this technique, 63 patients between the ages of 19 and 80 were examined. All patients had a palpable dorsalis pedis and posterior tibial artery.

of the 126 feet examined, 100 were essentially normal; i.e., individual release of the posterior tibial and the dorsalis pedis arteries produced the return of brisk pulse waves although somewhat lower amplitude than the waves seen with both arteries open (Figure 4).

In 13 of the feet ( 11 patients) compression of the posterior tibial artery produced a disappearance of the pulse wave although the dorsalis pedis artery was clearly pulsating (Figure 5). This would suggest that in about 18 per cent of this popula-

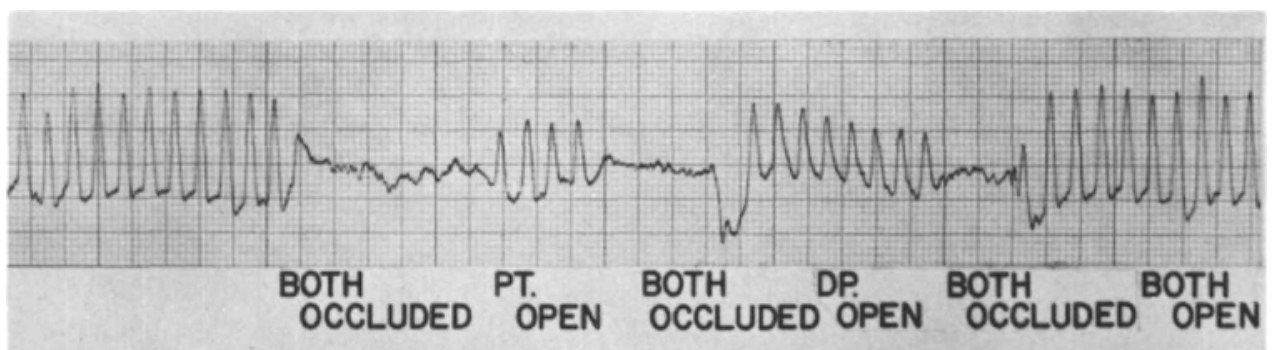

Figure 4. Showing normal response, i.e., return of good pulse wave when either the posterior tibial or dorsalis pedis artery are opened.

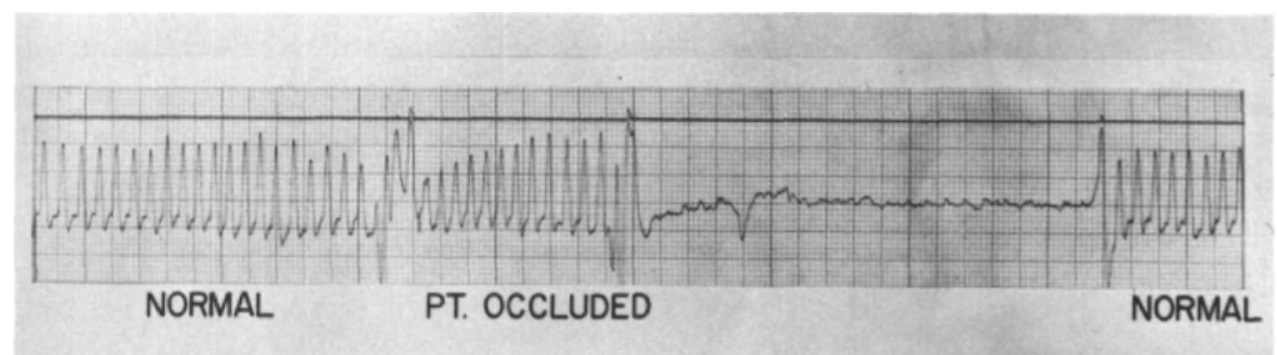

Figure 5. Abnormal response, occlusion of posterior tibial artery causes complete disappearance of pulse wave in spite of apparently patent dorsalis pedis artery. 


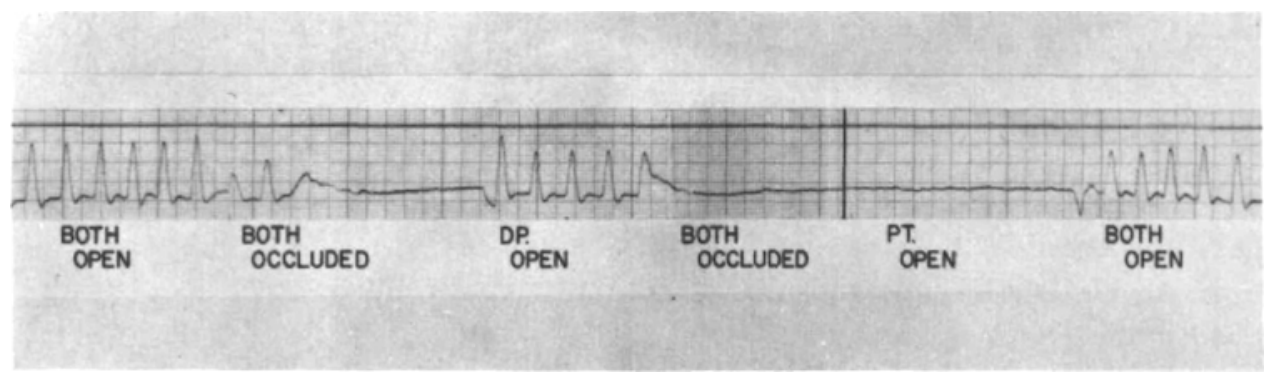

Figune 6. Normal pulse wave when dorsalis pedis open; the pulse does not return on opening of the posterior tibial artery.

tion, the dorsalis pedis artely, although clearly patent does not contribute significantly to the blood supply of the second toe.

In 13 feet ( 10 patients) occlusion of the dorsalis pedis artery alone caused complete disappearance of the pulse wave. It would appear that in about 16 per cent of patients the dorsalis pedis artery provides the main blood supply for the toes.

The records shown in Figures 4 to 6 represent examples for demonstration. It was observed that occasionally the pulse wave was initially absent but gradually re-appeared, indicating the opening up of a collateral circulation. Consequently, a negative response was not accepted unless after the occlusion of one artery, the pulse wave had remained absent for an observation period of two minutes.

In order to determine the reliability of dorsalis pedis artery pressures, simultaneously cannulations of the dorsalis pedis and the radial artery were carried out in five patients, using two precisely calibrated strain gauges and a 4-channel polygraph. Observations were made throughout the course of the neurosurgical operation at normotensive as well as hypotensive levels. Both transducers were placed at an identical level chosen as the height of the cerebral cortex. Both arteries were cannulated with a 16 gauge plastic needle (Jelco).

\section{RESULtS}

A sample of the tracings obtained are shown in Figure 7. The pulse pressure is usually somewhat higher in the dorsalis pedis than in the radial artery. The average difference between the mean pressures at normotension under halothane anaesthesia, was $4 \mathrm{~mm} \mathrm{Hg}$ (range 2.3 to $4.5 \mathrm{~mm}$ ). Although the pulse pressure at normotension was always higher in the dorsalis pedis artery the mean blood pressure was higher in the radial artery in three out of four patients. There was no change in this difference when the blood pressure was lowered to a level between 40 and 50 $\mathrm{mm} \mathrm{Hg}$.

In the one patient with arterial venous malformation, the blood pressure (Figure 8) fell precipitously due to blood loss. In this case, the pulse pressure during haemorrhagic hypotension was slightly greater in the radial artery while the mean pressure was an average of $7.5 \mathrm{~mm} \mathrm{Hg}$ higher than in the dorsalis pedis artery. The blood pressure was restored by transfusion and subsequently hypotension was 


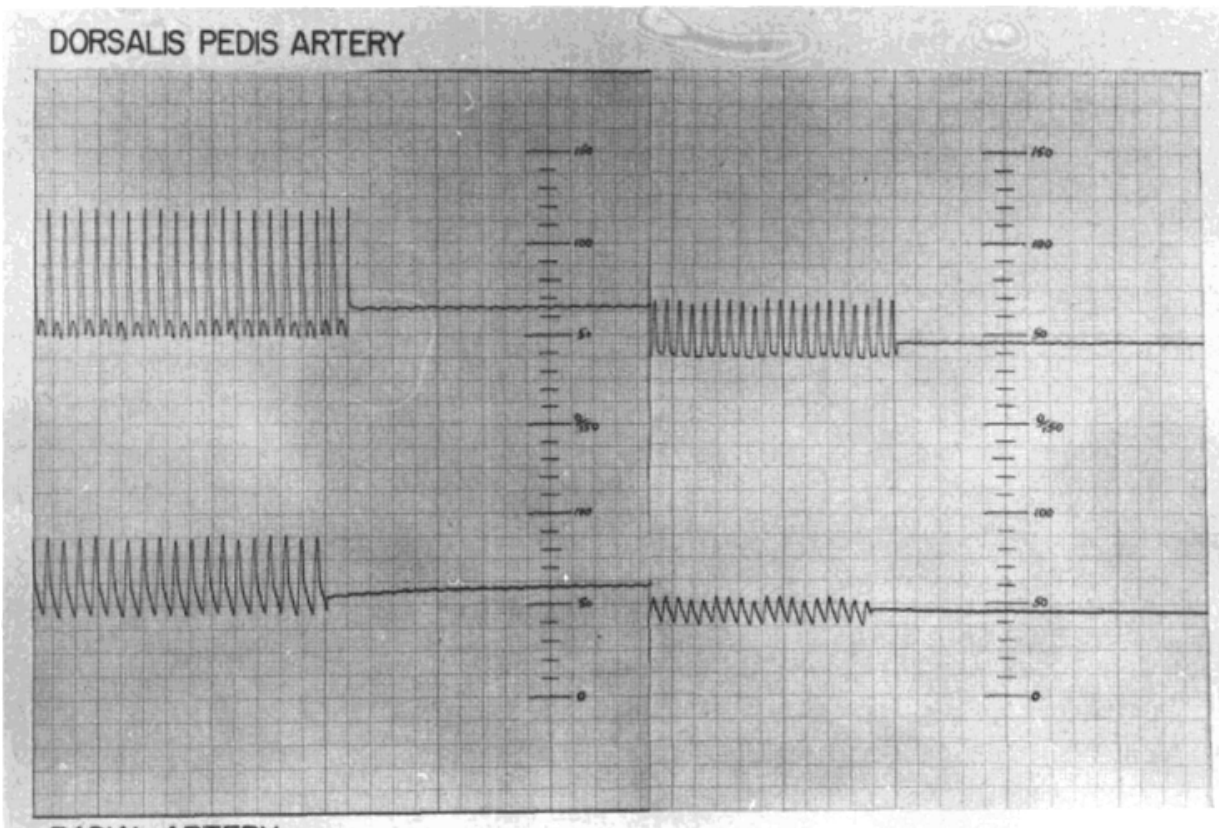

\section{RADIAL ARTERY}

Ficune 7. Upper tracing - dorsalis pedis artery. Lower tracing - radial artery. Left: normal blood pressure under nitrous oxide/halothane anaesthesia showing pulse pressure and mean arterial pressure. Right: hypotension induced with Arfonad.

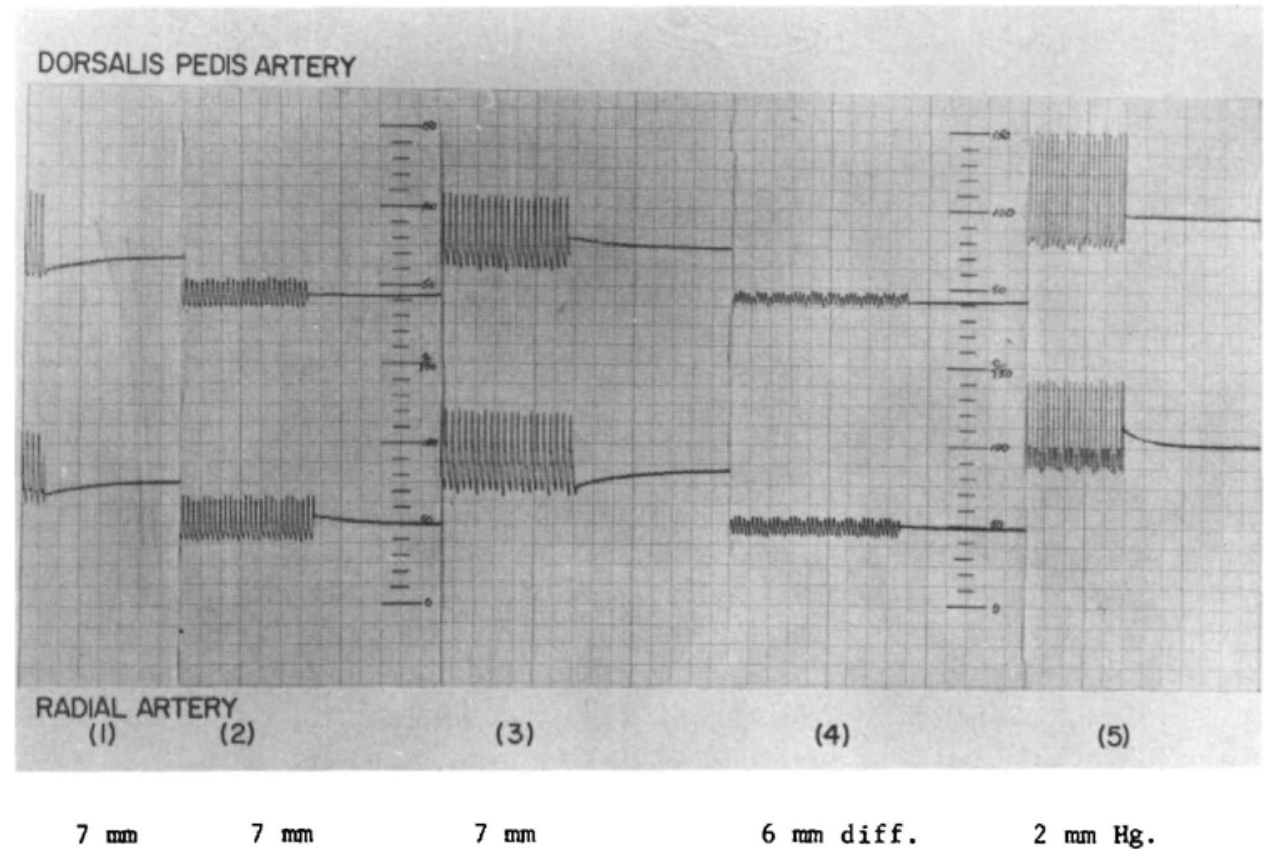

Figure 8. (1) Pulse pressure and mean pressure at normotensive level under nitrous oxide/halothane anaesthesia, (2) Hemorrhagic hypotension, (3) Restoration of pressure and blood volume, (4) Induced hypotension with Arfonad, (5) During closure of craniotomy. 
induced with Arfonad; again the pulse pressure was slightly higher in the radial artery, with a difference of $6 \mathrm{~mm} \mathrm{Hg}$ between the mean pressures. Towards the end of the operation, the pressure is again normal, showing the slightly greater pulse pressure in the dorsalis pedis artery and a difference in mean pressures of 2 $\mathrm{mm} \mathrm{Hg}$.

\section{Discussion}

The dorsalis pedis artery is located on the dorsum of the foot in a relatively mobile area, and is suitable for retention of an intra-arterial cannula. It appears to be congenitally absent in 12 per cent of the population. ${ }^{4,5}$ But we found that if the artery is distinctly palpable, it can be cannulated with a high degree of success.

The pulse pressure appears to be higher in the dorsalis pedis artery and consequently a difference between the two systolic pressures may be quite apparent (Johnstone and Greenhow). However, there is only a negligible discrepancy between the mean pressures in normotension and in induced hypotension.

Since we are using a mean arterial pressure to monitor artificial hypotension, there appears to be no contraindication in using the dorsalis pedis artery in place of the radial artery.

There are obviously a considerable number of anatomical variations; ${ }^{7}$ however, as long as the artery is palpable, these should make no difference. Of greater concern is the arrangement of the collateral circulation and particularly in the finding that in 16 per cent of the patients, in at least one foot, the dorsalis pedis appears to carry almost the entire blood supply to the toes. The clinical significance of this finding remains to be determined; our examination reflects acute occlusions while the result with prolonged occlusion may well be different and it seems likely that some collateral circulation would eventually develop, preventing the occurrence of an arterial insufficiency. In clinical practise of well over 100 cases we have not observed any complications following cannulation of the dorsalis pedis artery for the duration of neurosurgical procedures.

\section{SUMMARY}

The arteria dorsalis pedis, when clearly palpable, is a suitable artery for direct arterial blood pressure monitoring. The systolic pressure and the pulse pressure are likely higher in the dorsalis pedis artery when compared to the radial artery but there is no clinically significant difference in mean pressures. In plethysmographic studies it was found that in 16 per cent of the patients examined the pulse in the second toe disappeared after occlusion of the dorsalis pedis artery indicating that it carried the main blood supply to the toes. Although no complications have resulted from cannulation of the dorsalis pedis artery in our practise, some caution is in order and preliminary testing may be advisable even if the posterior tibial artery is distinctly palpable.

\section{RÉSUMÉ}

La pédieuse lorsqu'elle est facilement perçue est une bonne voie d'accès à la lecture directe de la pression artérielle. Les chiffres obtenus peuvent être légère- 
ment plus élevés que ceux obtenus dans une artère radiale, mais il n'existe pas de différence suffisante de la pression moyenne pour que cela ait une importance clinique. Lors d'études pléthysmographiques, on a trouvé que les pulsations du second orteil disparaissaient après occlusion de la pédieuse chez 16 pour cent des patients, l'irrigation des orteils étant surtout redevable à cette artère. Bien que n'ayant pas eu de complication chez nos malades avec cette méthode, il semble indiqué de vérifier au préalable la présence d’un pouls tibial postérieur perceptible.

\section{REFERENCES}

1. Conrad, Margaret C. Functional anatomy of the circulation to the lower extremities. Year Book Medical Publications Inc. Chicago (1971).

2. Cunningham, D.J. Textbook of anatomy. 11th ed. University Press, London (1972).

3. Gray, H. Anatomy of the human body. 29th ed. Lea \& Febiger, Philadelphia (1973).

4. Huber, J.F. The arterial network supplying the dorsum of the foot. Anat. Rec. 80: 373 (1941).

5. Barnhorst, B.A. \& Barner, H.B. Prevalence of congenitally absent pedal pulses. N.E.J.M. 278: 264-265 (1968).

6. Johnstone, R.E. \& Greenhow, D.E. Catheterization of the dorsalis pedis artery. Anesthesiology 39: 654 (1973).

7. KeEn, J.A. A study of the arterial variations in the limbs, with special reference to symmetry of vascular patterns. Amer. J. Anat. 108: 245 (1961). 